\title{
К СТРАТИГРАФИИ ПО КОНОДОНТАМ НИЖНЕГО И НИЗОВ СРЕДНЕГО ОРДОВИКА СЕВЕРО-ЗАПАДНОИ ЛАТВИИ
}

Среди важных для стратиграфии групп фауны ордовика конодонты как элементы пелагических конодонтонесущих организмов имеют первостепенное значение для корреляции разнофациальных отложений. Большая заслуга в изучении конодонтов ордовика Латвии принадлежит В. Вийра, Р. Ульст, Л. Гайлите.

Анализ конодонтов ордовика Латвии, начатый В. Вийра (1974) и продолженный Л. Гайлите и Р. Ульст (1975), позволил установить аналогию между конодонтовыми комплексами Латвии и комплексами, описанными в Ленинградской области С. П. Сергеевой, в Эстонии В. Вийра (1974) и в Швеции М. Линдстрёмом (Lindström, 1954, 1971). Некоторым дополнением к этому является материал, полученный нами по двум скважинам Северо-Западной Латвии.

Выбор скважин определен их фациальной принадлежностью (рис. 1): отложения в разрезе скв. Рагациемс, расположенной в полосе северозападного склона Елгавского прогиба, представляют собой ШведскоЛатвийский (глинисто-карбонатный) тип ордовика, в то время как более мелководный, карбонатный разрез скв. Вентспилс на юго-восточном склоне Готландского поднятия позволяет отнести его отложения к Прибалтийскому (карбонатному) типу ордовика Прибалтики (Материалы . . ., 1976, с. 36). Мощность отложений данного временного интервала равна в скв. Вентспилс 33 м и в скв. Рагациемс 73 м. Цератопигевые отложения в разрезе скв. Вентспилс залегают с размывом на алевритисто-песчаных породах кембрия, а в разрезе скв. Рагациемс согласно на глинисто-песчаных породах пакерортского горизонта (рис. 2).

Распределение конодонтов и корреляции разрезов на основании полученных комплексов показаны в таблице и на рис. 2. Соответствие между стратиграфическими подразделениями и конодонтовой зональностью (рис. 2) дано по Вийра (1974), Дзику (Dzik, 1976, 1978), и Линдстрёму (Lindström, 1971). Корреляционные связи между разрезами следующие. Слои 1-3 разреза Рагациемс и слой 1 разреза Вентспилс несут цератопигевый комплекс Scandodus varanguensis. Пачки 1, 2, 3 скв. Рагациемс, представленные комплексом Paroistodus proteus, соответствуют хуннебергскому подгоризонту. Вполне возможно, что глауконитовый

Рис. 1. Схема палеоструктурного районирования Латвии в раннем ордовике (Гайлите, Ульст, 1975). І $a-$ осевая часть Елгавского прогиба, Іб - склоны Елгавского прогиба, II - юго-восточный склон Готландского поднятия; III - раннеордовнкское поднятие в Юго-Восточной Латвии; 1 - скв. Вентспилс, 2 - скв. Рагациемс.

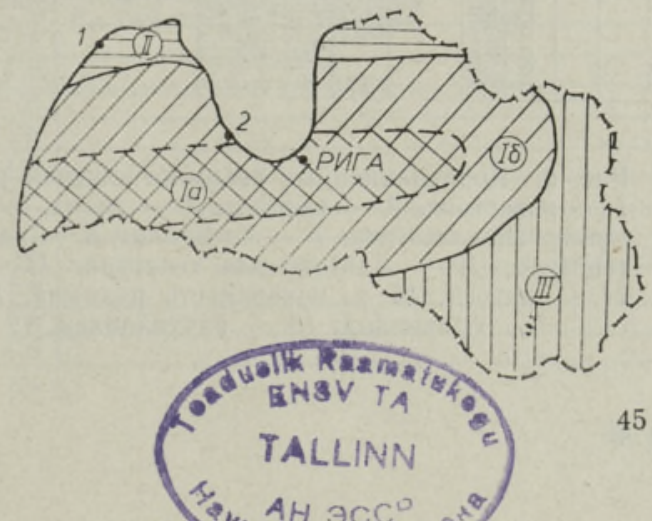




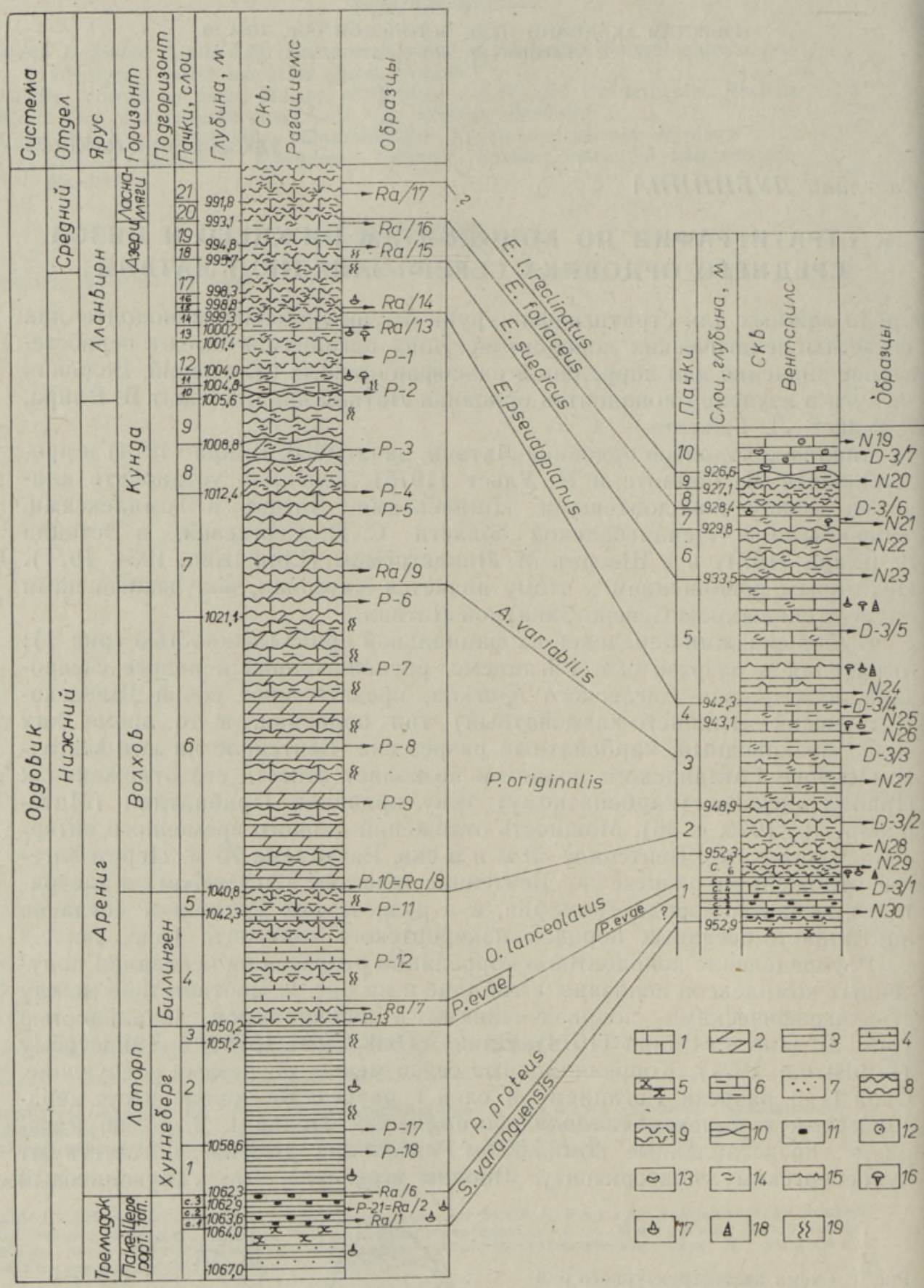

Рис. 2. Корреляционные взаимоотношения разрезов скважин Вентспилс и Рагациемс. 1 - известняк, 2 - мергель, 3 - глина, 4 - известковая глина, 5 - песчаник, 6 глинистый известняк, 7 - алевролит, 8 - комковатая текстура, 9 - неяснокомковатая текстура, 10 - линзовидная текстура, 11 - глауконит, 12 - оолиты, 13 - пирит, 14 - детрит, 15 - поверхность размыва, 16 - находки трилобитов, 17 - находки брахиопод, 18 - наутилоидеи, 19 - вертикальные ходы илоедов. 


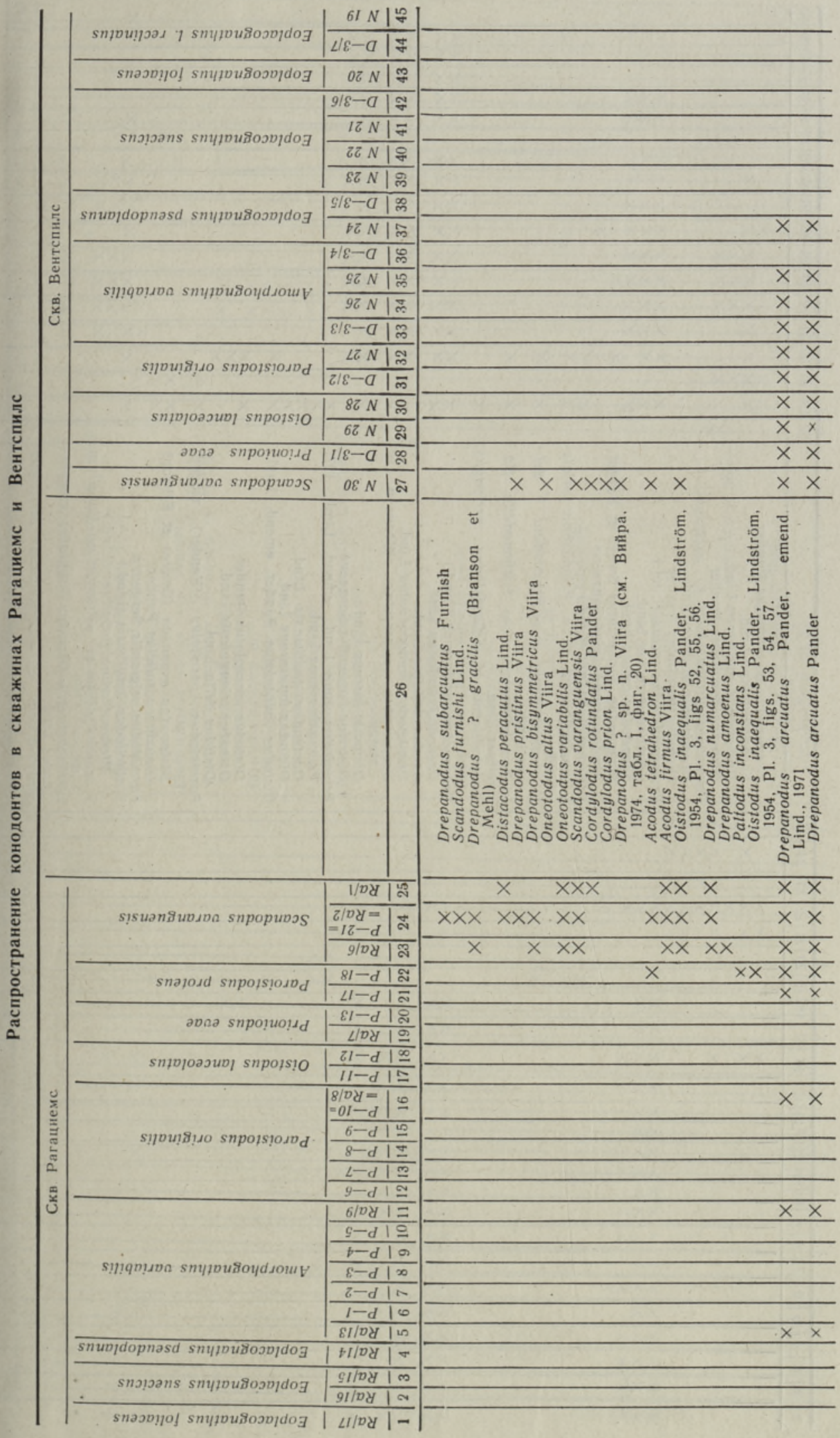




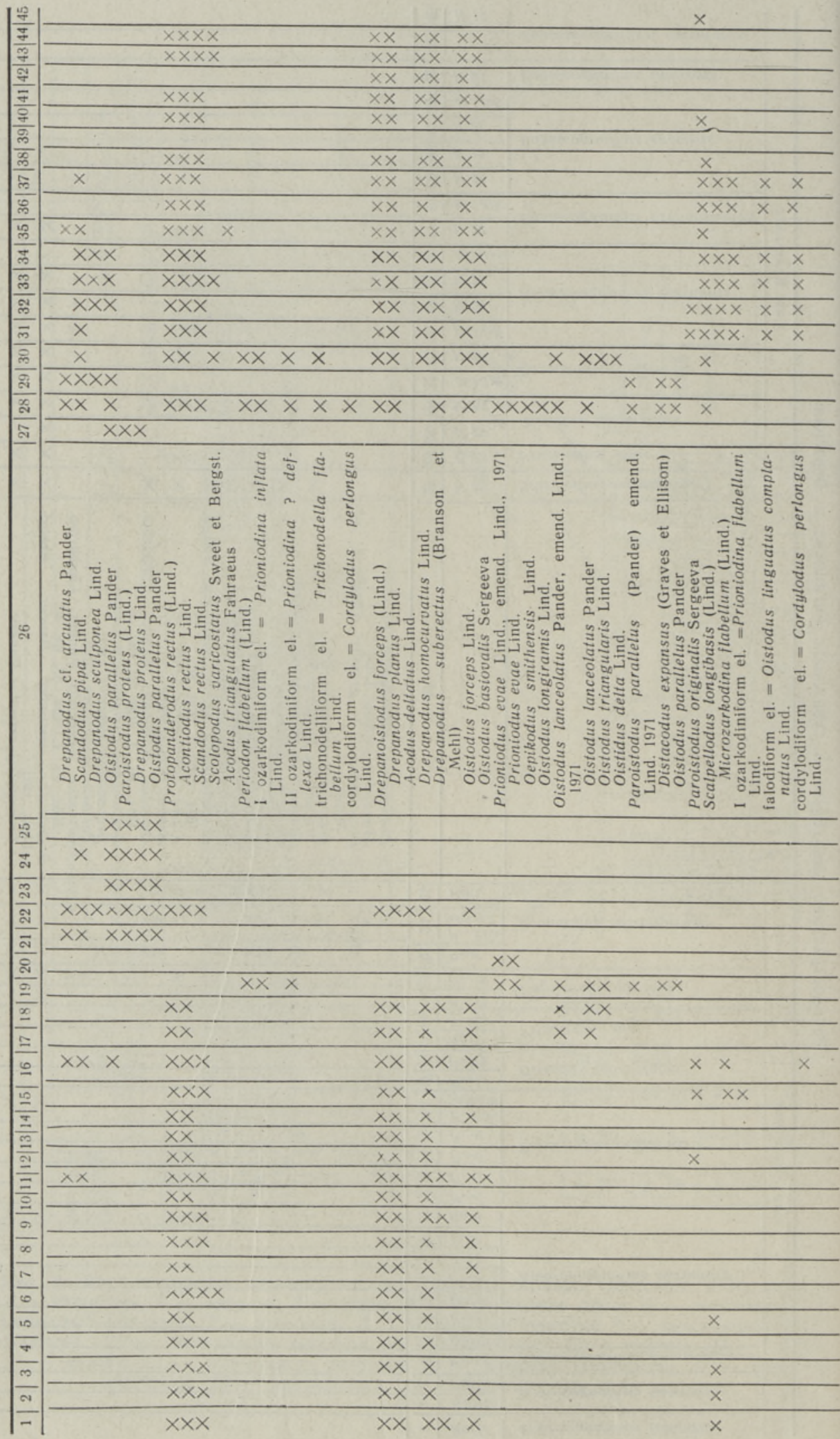




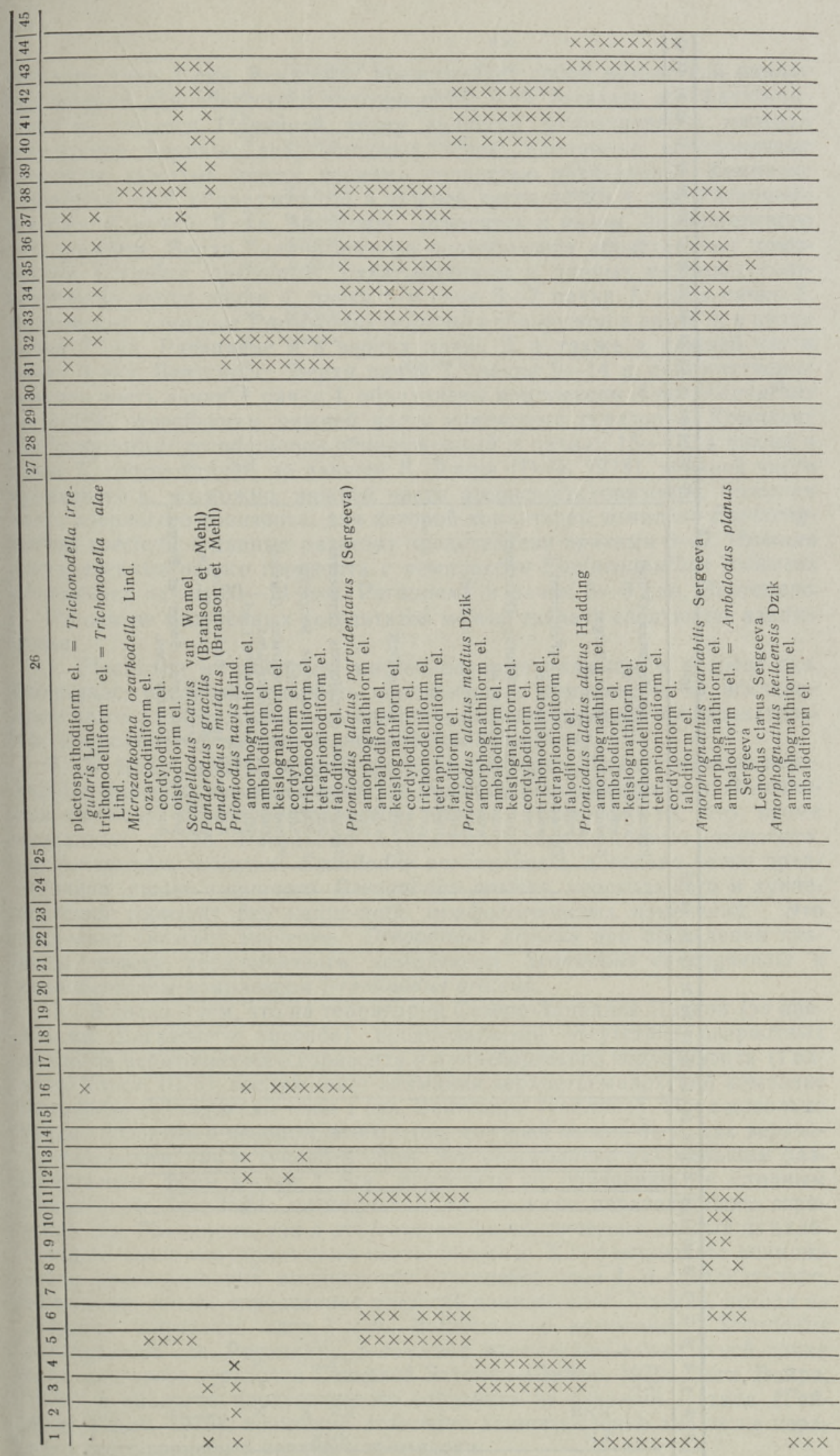



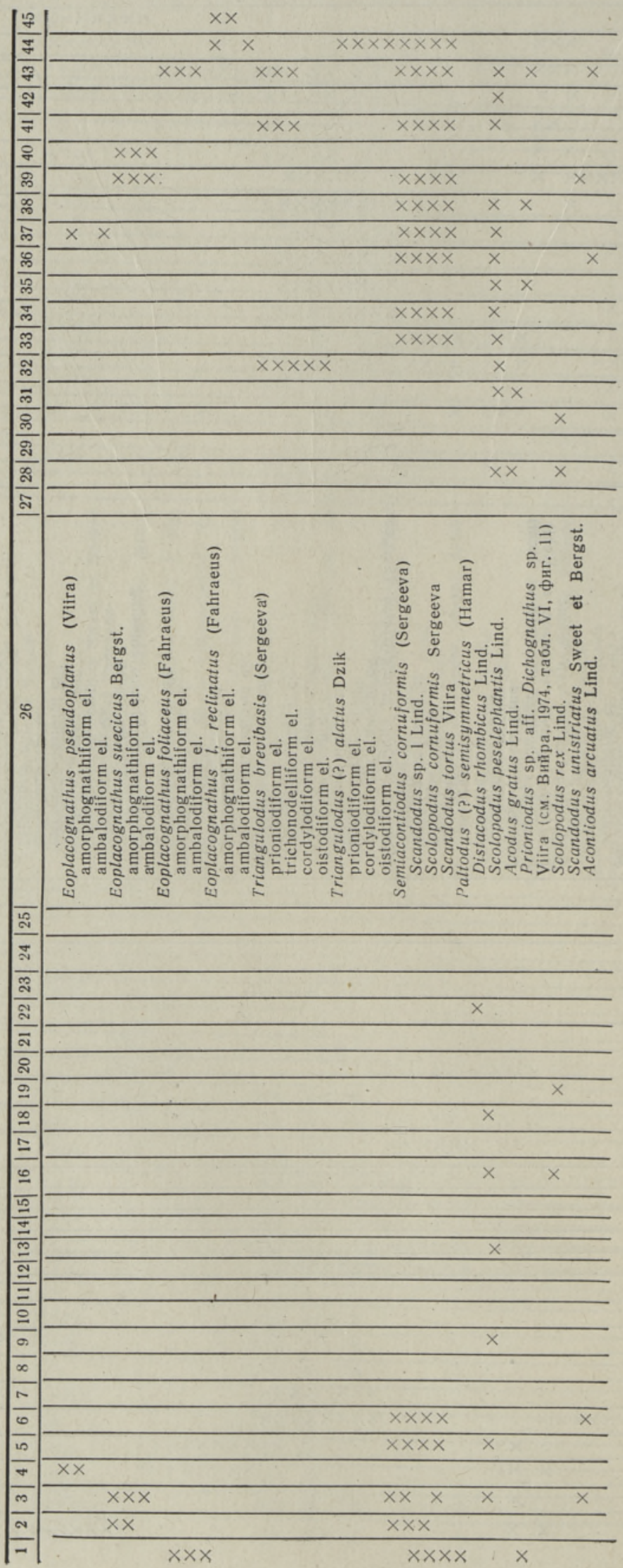
песчаник слоя 3 скв. Вентспилс представляет собой возрастной аналог отложениям хуннебергского подгоризонта, хотя доказать это фаунистически не удается. Причиной этому является необыкновенно плотная цементация крупных глауконитовых зерен; единичные конодонтовые элементы, зажатые между зернами полностью раздавлены. Комплекс Prioniodus evae, обнаруженный в нижней части пачки 4 скв. Рагациемс и в слое 4 пачки 1 скв. Вентспилс, относится к низам биллингенского подгоризонта. Верхи биллингенского подгоризонта представлены комплексом Oistodus lanceolatus, охватывающим в данных разрезах соответственно верхи пачки 4, пачку 5 и слои 5-7 пачки 1, низы пачки 2. Волховский комплекс Paroistodus originalis обнаружен в пачке 6, в низах пачки 7 скв. Рагациемс и в верхах пачки 2, а также в нижней части пачки 3 скв. Вентспилс. Верхи пачки 7, пачки 8-14 и соответственно верхняя часть пачки 3 , пачка 4, объединены комплексом Amorphognathus variabilis, отвечающим нижней части кундаского горизонта. Комплекс Eoplacognathus pseudoplanus, обнаруженный в пачках 15-17, а также в пачке 5 , соответствует, по данным Е. Дзика (Dzik, 1978), верхней части кундаского и, возможно, нижней части азериского горизонта. Болытая часть азериского горизонта, для которой характерен комплекс Eoplacognathus suecicus, в данных разрезах представлена пачками 6-7. Нижняя часть ласнамягиского горизонта с комплексом Eoplacognathus foliaceus объединяет пачки 20-21 скв. Рагациемс и пачки 8-9 скв. Вентспилс.

На основе полученных результатов можно сделать следующие заключения.

1. Несмотря на“довольно многочисленные размывы в разрезе скв. Вентспилс, последовательность конодонтовых комплексов, за исключением низов разреза, оказалась полной и соответствующей последовательности в более глубоководном разрезе скв. Рагациемс.

2. В. Вийра (1974) в цератопигевом горизонте были отмечены переходные морфологические формы от Drepanodus numarcuatus к Drepanodus amoenus «протеусообразного» облика. Интересно то, что кроме названных в скв. Рагациемс в аналогах цератопигевого горизонта, заключающего комплекс Scandodus varanguensis, довольно четко представлена линия типичного Drepanodus proteus, переходящего в хуннебергский горизонт без каких-либо морфологических изменений. Это несколько снижает значение Drepanodus proteus при проведении границы между цератопигевым комплексом Scandodus varanguensis и хуннебергским комплексом Drepanodus proteus.

3. В связи с тем, что на территории Северо-Западной Латвии (за пределами Елгавского прогиба) предполагается отсутствне возрастных аналогов цератопигевого горизонта и хуннебергского подгоризонта (Гайлите, Ульст, 1975), заслуживает внимания верхнетремадокский комплекс Scandodus varanguensis слоя 1 скв. Вентспилс (таблица). Пока довольно трудно говорить о возрасте этого слоя, который может быть как верхнетремадокским, так и хуннебергским. Это обусловлено как меньшим разнообразием форм в слое 1 скв. Вентспилс по сравнению со сходным комплексом Scandodus varanguensis из аналогов цератопигевого горизонта скв. Рагациемс, так и отсутствием фаунистических данных из залегающего выше глауконитового песчаника слоя 3 , что исключает возможность прослеживания сменяемости комплекса слоя 1, а следовательно, затрудняет точное определение возраста данного слоя. Однако, исходя из сходства комплекса слоя 1 скв. Вентспилс с комплексом Scandodus varanguensis скв. Рагациемс, а также с комплексом варангуской пачки цератопигевого геризонта Северной Эстонии (Вийра, 1970; Мяги, Вийра, 1976) и аналогов цератопигевого горизонта из скважин Латвии (Гайлите, Ульст, 1975), возможно отнесение данного слоя к аналогам цератопигевого горизонта верхнего тремадока. 
Наиболее полные данные о конодонтах пограничных слоев цератопигевого и латорпского горизонтов по Северной Эстонии приведены В. Вийра. При этом Acodus tetrahedron, Scandodus varanguensis и Drepanodus pristinus, характерные только для варангуской пачки (Вийра, 1970; Мяги, Вийра, 1976) и обнаруженные в слое 1, подтверждают его отнесение к верхнему тремадоку.

4. Результаты, полученные по этим двум скважинам Северо-Западной Латвии, подтверждают, несомненно, ту же последовательность конодонтовых комплексов, которая была представлена ранее при изучении многочисленных разрезов балтийского типа В. Вийра (1974), Л. Гайлите и Р. Ульст (1975), Е. Дзиком (Dzik, 1976, 1978), М. Линдстрёмом (Lindström, 1954, 1971).

\section{Л И Т Е РА Т У Р А}

Вийра В. Конодонты варангуской пачки (верхний тремадок Эстонии). - Изв. АН ЭССР. Хим. Геол., 1970, 19, 224-233.

Buйра В. Я. Конодонты ордовика Прибалтики. Таллин, 1974.

Гайлите Л. К., Ульст Р. Ж Ж. Стратиграфия и фауна нижнего ордовика Латвии. - В кн.: Геология кристаллического фундамента и осадочного чехла Прибалтики. Рига, $1975,82-131$

Материалы по стратиграфии Прибалтики (К Межведомственному стратиграфическому совещанию). Вильнюс, 1976, 36-37.

Мяги C., Buйра B. Распространение конодонтов и беззамковых брахиопод в цератопигевом и латорпском горизонтах Северной Эстонии. - Изв. АН ЭССР. Хим. Геол,, $1976,25,312-318$.

Dzik, J. Remarks on the evolution of Ordovician conodonts. - Acta Paleont. Polon., $1976,21,395-456$.

Dzik, J. Conodont biostratigraphy and paleogeographical relation of the Ordovician Mojcza Limestone (Holy Cross Mts, Poland). - Acta Paleont. Polon., 1978, $23,51-72$.

Lindström, M. Conodonts from the lowermost Ordovician strata of South-Central Sweden. - Geol. Fören. Stockholm Förhandl, 1954, 76, 517-604.

Lindström, M. Lower Ordovician conodonts of Europe: Symposium on Conodont Biostratigraphy. - Geol. Soc. Amer., 1971, 127, 21-61.

Геологический институт

Академии наук СССР

Поступнла в редакцию 5/IV 1982

\section{Svetlana DUBININA}

\section{LOODE-LÄTI ALAMORDOVIITSIUMI JA KESKORDOVIITSIUMI ALUMISE OSA STRATIGRAAFIAST KONODONTIDE ALUSEL}

On võrreldud kaht Loode-Läti alamordoviitsiumi ja keskordoviitsiumi alumise osa läbilõiget, mis esindavad erinevaid struktuurilis-fatsiaalseid vööndeid. Tseratopüüge, latorpi, volhovi, aseri ja lasnamäe lademe piires on eristatud 10 konodonditsooni.

\section{Svetlana DUBININA}

\section{CONODONT STRATIGRAPHY OF THE LOWER ORDOVICIAN AND THE LOWER PART OF THE MIDDLE ORDOVICIAN IN NORTH-WEST LATVIA}

The author presents data on the distribution of the Tremadocian, Arenigian and Llanvirnian conodonts from two sections (Ragaciems and Ventspils borings) of NorthWest Latvia. It has become evident that the Lower Ordovician conodont zones of Sweden, Estonia and Leningrad Region are rather well represented in North-West Latvia. The location of the borings is shown in Fig. 1. The distribution of conodonts and the correlation of the two sections discussed are presented in the Table and Fig. 2. 